\title{
Hypomelanosis of Ito associated with mosaicism for trisomy 7 and apparent 'pseudomosaicism' at amniocentesis
}

\author{
D Jenkins, K Martin, I D Young
}

\begin{abstract}
We describe a patient with hypomelanosis of Ito (HI) and typical characteristics. Cytogenetic analysis of fibroblast cultures showed mosaicism for trisomy 7 . The trisomy cell line was first observed in an amniotic fluid culture and illustrates the problem of distinguishing pseudomosaicism from true mosaicism.

( $\mathcal{A}$ Med Genet 1993;30:783-4)
\end{abstract}

Hypomelanosis of Ito (HI) was first described by Ito in $1952 .^{1}$ It is a rare neurocutaneous disorder characterised by a swirling pattern of hypopigmentation of the skin, shown to follow the lines of Blaschko. HI was subsequently named incontinentia pigmenti achromians because of the resemblance in pattern to incontinentia pigmenti. HI has been observed in many ethnic groups. In addition to the pigmentary pattern, $74 \%$ of the reported patients have one or more abnormalities of the CNS, eyes, hair, teeth, or musculoskeletal system, although there is no consistent clinical pattern.

We report a patient with HI, mild developmental delay, and facial asymmetry with mosaicism for trisomy 7 . In addition, apparent pseudomosaicism for trisomy 7 was observed prenatally at amniocentesis.

\section{Case report}

The patient, an 8 year old white male, was delivered at 38 weeks' gestation with a birth weight of $3700 \mathrm{~g}$. He was described as a placid baby and had no major problems in infancy or early childhood other than recurrent middle ear infection. He first walked at 15 months and began talking at 2 years. By the age of 4 years his behaviour had become 'difficult' with poor concentration and occasional episodes of bad temper. Temporal lobe epilepsy was diagnosed at 7 years when he was referred for investigation for mild developmental delay and behavioural disturbance which was most marked at school where he was restless, disruptive, and at times aggressive.

On examination aged 7 years, height, weight, and head circumference all fell on or close to the 50th centile. Notable features included a prominent forehead with facial asymmetry, bifid uvula, poor dentition with enamel dysplasia, and widespread streaks of depigmentation on the back and limbs which followed Blaschko's lines and were best visualised under UV light (figure).

\section{CYTOGENETIC INVESTIGATIONS}

The proband's mother was referred for amniocentesis for raised maternal serum AFP (a finding which has been reported in a case of $\mathrm{HI}$ by Turleau et $a l^{2}$ ). Cytogenetic analysis showed trisomy 7 in $9 / 9$ cells from one culture but in $0 / 30$ cells from a second culture. The trisomy 7 cell line was presumed, at this time, to be a cultural artefact. When the proband was aged 7 a blood specimen referred for cytogenetic analysis showed an apparently normal male karyotype in all 60 cells examined. At the age of 8 a skin biopsy from the

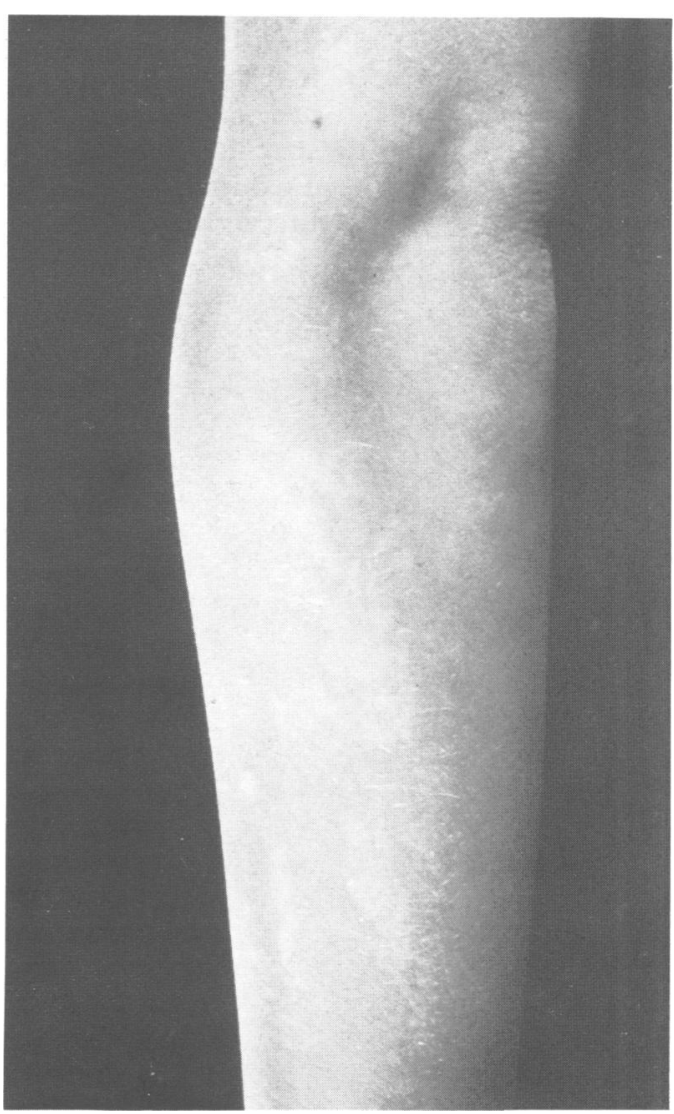

View of the patient's arm showing longitudinal streaks of depigmentation. 
patient's arm was referred for cytogenetic analysis. Multiple cultures were established from the sample. The overall culture quality and growth rate was relatively poor. Trisomy 7 was detected in 26/36 cells from two separate cultures, with the minority of cells showing a normal male karyotype.

No cell line from this patient has been maintained.

\section{Discussion}

Hypomelanosis of Ito (HI) is a curious disorder in which basal cell pigmentation may be either increased or decreased. Affected subjects have two clones of cells with varying pigmentary potential. If such clones are established before the primitive streak stage then failure of migration of melanoblasts could lead to reduced numbers of melanocytes resulting in the hypopigmentary pattern following the lines of Blaschko. ${ }^{3}$

The observation that the skin markings follow the lines of Blaschko has led to the hypothesis that all cases are the result of mosaicism or chimerism. Happle ${ }^{4}$ has shown that females heterozygous for several $\mathrm{X}$ linked conditions, such as IP and $\mathrm{X}$ linked dominant chondrodysplasia punctata syndrome, have skin variations following Blaschko's lines, as a result of lyonisation which occurs shortly before or at the time of the formation of the primitive streak. Any event which produces a mixed population of cells at the time of lyonisation will produce the pattern observed in heterozygous females for X linked disorders. ${ }^{5}$

A variety of chromosomally mosaic cell lines has been observed in $\mathrm{HI}$ including aneuploidies, translocations, deletions, rings, and diploid/triploid cell lines. Such findings led Flannery et $a l^{6}$ to propose that HI may be a nonspecific indication of chromosomal mosaicism. To our knowledge the case now reported is the first in which trisomy 7 has been found in $\mathrm{HI}$, an observation which lends further support to the original hypothesis of Flannery et al ${ }^{6}$ that $\mathrm{HI}$ is a marker for underlying chromosome mosaicism/chimerism.

This case is also unusual in that it illustrates the difficulty associated with distinguishing between pseudomosaicism, defined as an abnormal cell line in a single culture only, and true mosaicism in which the abnormal cell line is identified in more than one culture. Hsu and Perlis $^{7}$ quoted an incidence for pseudomosaicism in prenatal diagnosis of $3.25 \%$ as compared to $0.25 \%$ for true mosaicism. In this survey trisomy 7 accounted for $11 \cdot 1 \%$ of all cases of pseudomosaicism indicating that this is a relatively common cultural artefact. The findings in the patient reported here show that 'apparent' pseudomosaicism for trisomy 7 may also rarely reflect true fetal mosaicism, an observation of very real practical importance in the counselling situation.

We would like to thank Dr F N Porter of Grantham and Kesteven General Hospital, Grantham, for referring this patient, and Dr $M$ Whitehouse and Mrs C Cooper of the Cytogenetics Department, City Hospital, Nottingham for their time and interest.

1 Ito $M$. Studies on melanin. XI. Incontinentia pigment achromians. A singular case of nevus depigmentosus syste2 maticus bilaterus. Tohoku f Exp Med 1952;55(suppl):57-9. JC, de Grouchy J. Hypomelanosis of Ito (incontinentia $\mathrm{JC}$, de Grouchy J. Hypomelanosis of Ito (incontinentia pigmenti achromians) and mosaicism
of 15q1. Hum Genet 1986;74:185-7.

3 Ross DL, Liwnicz BH, Chun RW, Gilbert E. Hypomelanosis of Ito (incontinentia pigmenti achromians). A clinicopathologic study: macrocephaly and grey matter heterotropies. Neurology 1982;32:1013-16.

4 Happle R. Lyonisation and the lines of Blaschko. Hum Genet 1985;70:200-6.

5 Donnai D, Read AP, McKeown C, Andrews T. Hypomelanosis of Ito: a manifestation of mosaicism or chimerism. $f$ Med Genet 1988;25:809-18.

6 Flannery DB, Byrd JR, Freeman WE, Perlman SA. Hypomelanosis of Ito: a cutaneous marker of chromosomal mosaicism. Am ₹ Hum Genet 1985;37:A93.

$7 \mathrm{Hsu}$ LYF, Perlis TE. United States survey on chromosome mosaicism and pseudomosaicism in prenatal diagnosis. Prenat Diagn 1984;4:97-130. 